\title{
Squamous Cell Carcinoma of the Head and Neck in the Elderly
}

\author{
Morten Boysen ${ }^{*}$
}

Department of Oto-laryngology, Head and Neck Surgery, Rikshospitalet, Faculty of Medicine, University of Oslo, Norway

\begin{abstract}
Background: Increasing life expectancy and incidence of head and neck carcinomas, including some types of head and neck malignancies, lead to a constantly higher proportion of old oncologic patients. Previous reports regarding the outcome for elderly patients with head and neck carcinomas squamous cell carcinoma (HNSCC) are controversial. For further insight, a large single-institution material has been analysed.
\end{abstract}

Material: Prospective recording of demographic details, continuous follow-up and determining exact cause of deaths of patients with carcinoma of the head and neck have been in progress over a period of 14 years. Having excluded 154 patients $(7.3 \%)$, who did not follow-up, who had distant metastases at diagnosis, or who had received extensive treatment for a previous head and neck carcinoma or who refused treatment, or for medical or mental reasons, were unable to receive curative treatments. The material includes 1944 patients, of whom 37\% received combined treatment, 58\% radiotherapy alone and $6 \%$ surgery alone. The mean age was 65 years with a mean follow-up of 3.8 years. The material was divided into two groups; $\leq 65$ and $>65$ years of age and analysed by means of $X^{2}$ tests and log-rank $X^{2}$ tests.

Results: Early stage primary tumours and a more advantageous $\mathrm{N}$ - classification were more conspicuous among the older patients $(\mathrm{p}=0.2406$ and $\mathrm{p}<0.0002)$. The group of patients $\leq 65$ years had a significantly better disease-specific survival rate compared to the older patients $(\mathrm{p}=0.145)$. However, $40 \%$ of the older patients were alive with no evidence of disease. By comparing 65-74 patients with patients' $\geq 76$ years of age, a p-value of 0.0105 was obtained in favour of the younger group, but still an appreciable number of the older patients escaped their HNSCC.

Conclusion: Given a satisfactory mental and physical condition, patients older than 65 years had a reasonable diseasespecific survival. It is therefore no reason to withhold appropriate treatment for the elderly, fit patients which could prevent or delay the misery and devastating situation, as well as a reduction in the heavy expenditures that patients with persistent or recurrent head and neck tumours represent.

Keywords: Head and neck carcinoma, geriatrics, oncology prognosis, survival, treatment.

\section{INTRODUCTION}

Squamous cell carcinoma of the head and neck (SCCHN) is generally considered a disease of the late middle- aged and elderly people. The literature abounds with bewildering reports of the effect of advanced age on survival and other tumour parameters [1]. Because this group of people is the fastest growing population segment in Europe and North America, a steadly increasing incidence of malignant tumours, including in some sites within the head and neck region, an increasing number of older patients with SCCHN is anticipated. In light of this and the escalating expenditures connected to medical care, it is important to determine the impact of appropriate treatment on the disease-specific survival in elderly patients.

Based on continuous prospective recording of relevant clinical information and complete follow-up collected over a period of 14 years, the disease specific- survival for SCCHN of the upper aero- digestive tract was analysed in relation to age at the diagnosis.

*Address correspondence to this author at the Department of Otolaryngology, Rikshospitalet, University of Oslo, 0027, Oslo, Norway; Tel: 23075342; Fax: 23074260;

E-mails: morten.boysen@rikshospitalet.no and moboysen@online.no

\section{PATIENTS AND METHODS}

From 1983 through 1997, the author has, in prospective manner, collected relevant clinical information, follow-up and the exact cause of death for all patients with malignant disease of the head and neck admitted to our institution. Classification was initially performed according to the $3^{\text {rd }}$ edition (1982) of the International Union against Cancer (UICC). The database has recently been updated to the 1997 $\left(4^{\text {th }}\right)$ edition of UICC. The registration has through the years been equivalent to certainty factor 2 (UICC, $6^{\text {th }} \mathrm{Ed}$ ).

The database comprises of a total of 2096 patients with histologically verified squamous cell carcinoma of the upper aero-digestive tract (lips and salivary glands not included) treated at the Department of Otolaryngology, Rikshospitalet, in close collaboration with the Norwegian Radiumhospital, a tertiary referral centre that recruits patients from the SouthEastern part of Norway, with approximately 1.5 million people. Excluded from this evaluation were 154 patients (7.3 $\%$ ) who did not receive any treatment with curative intent. The reasons for abstaining from treatment were either distant metastases of the actual tumour, a refusal of treatment, or other serious diseases corresponding to the ASA physical indexing (American Society of Anaesthesiology), an ASA index exceeding $\geq 4$ (life threatening diseases, not necessarily related to the primary disease) [2], or mental disorders that 
made curative treatment impossible, previous extensive treatment for a malignant head and neck tumour, for whom the treatment options were exhausted and one patient lost to follow-up. Age alone has never been a reason to abstain from treatment. For obvious reasons, the number of patients not receiving treatment was highest in the group of patients older than 65 years (Table 1). Some of the patients excluded received some kind of palliative treatment. All these patients died either from their HNSCC or co-morbidity within 2 years. The material (Table 1) thus comprises of 1944 eligible patients with squamous cell carcinoma of the oral cavity, oro-, epi- and hypopharynx, sino-nasal cavity, larynx and neck metastases with unknown primary tumour (ICD9; 141,143,144 146 147, 148, 149,160, 161 and 196).

Table 1. Material According to Age Groups

\begin{tabular}{|c|c|c|c|c|}
\hline \multirow{2}{*}{ Patients } & \multicolumn{2}{|c|}{ Age Groups } & \multirow{2}{*}{ Total Sum } & \multirow{2}{*}{ Statistics } \\
\hline & $\leq 65 y$ & $>65 y$ & & \\
\hline No of pat. withHNSCC & 1087 & 1009 & 2096 & $\mathrm{p}=0.1865$ \\
\hline $\mathrm{M}+$ at diagnosis & 1 & 1 & 2 & \\
\hline Lost to follow-up & & 1 & & \\
\hline previous head and neck & & & & \\
\hline carcinoma; no treatment. & 15 & 55 & 70 & $\mathrm{p}<0.001$ \\
\hline Unfit for treatment; & & & & \\
\hline$(\mathrm{ASA} \geq 3)$ & 30 & 51 & 81 & $\mathrm{p}=0.0018$ \\
\hline No. of pat. excluded & 46 & 108 & 154 & \\
\hline No. of pat. treated & & & & \\
\hline with curative intent. & 1043 & 901 & 1944 & $\mathrm{p}=0.1895$ \\
\hline
\end{tabular}

The mean age was 65 years (from 20 to 92 years). A cutoff age of 65 years was therefore chosen, resulting in two age groups of approximately equal size ( $\leq 65$ and $>65$ years), enabling comparison and statistical analysis. Information regarding tobacco and alcohol abuse has not been recorded.

Complete follow-up and accurate cause of death were obtained by, review of outpatient and hospital charts, autopsy findings (when performed), direct contact with the local hospitals, family physicians, direct contact with patients or next to kin. The mean follow-up time was 3.8 years, but never less than 3 years [3].

Since 1983 the author holds an authorization from the Norwegian Data Inspectorate to collect and evaluate data from patients admitted to our department. The local Ethical Committee and the Ministry of Health and Welfare have approved the study. There is no conflict of interest.

Treatment was planned in a joint, clinical meeting with radiation oncologist, head and neck surgeons, pathologists and a nurse specialized in oncology. Initially the patients were treated with radiotherapy alone, or radiotherapy followed by surgery, when this was planned, or in cases of residual loco-regional tumor manifestations 6 weeks after completion of radiotherapy. In 1991 we revised our treatment policy, and since then surgery has played an increasingly grater role. Whenever possible, we now prefer surgery, followed by radiotherapy, for most tumours, decided by primary tumour size, unfavourable histological spread, such as violated resection margins or an infiltration depth of the primary tumour exceeding $3 \mathrm{~mm}$ or a spread to cervical glands. The neck has, as a rule, been treated together with the primary tumour. Neo-adjuvant chemotherapy with cisplatin and 5-fluorouracil, according to a Nordic protocol [4] was administered to 53 patients. Tumours of advanced stage were otherwise treated by radiotherapy alone. Radiotherapy was generally given in fractions of 2 Gy/day 5 days a week from a high voltage source. The primary site received 60-70 Gy and the neck 50-60 Gy over a period of 57 weeks.

\section{Statistics}

The data were stored and analysed by means of SAS software (SAS Institute, Cary, NC). $X^{2}$ tests were performed for categorical data. Kaplan-Meyer plots were used to illustrate the disease-specific survival and the log-rank procedure, to test the effect of age on the disease-specific survival. A case was censored if death resulted from diseases other than the original tumour, or if the patient was alive with no evidence of the original tumour at the last follow-up contact/consultation. P-values $<0.05$ were considered statistically significant.

\section{RESULTS}

Table 2 presents the clinical data and treatment. Men outnumbered women in both age groups $(\mathrm{p}<0.001)$.

There was no evident difference in the T-classification. An advantageous $\mathrm{N}$-classification favouring the older patients resulted in a significant stage distribution. It should, however, be noted that the material includes 145 patients with T1a glottic carcinoma (all N0), who since 1996 have preferably were treated with $\mathrm{CO}_{2}$ laser surgery. As T1a glottic squamous cell carcinomas rarely metastasize, there is a distinct skew towards early T-stage and N0 in both age groups. Having excluded these carcinomas, the Tdistribution turned out to be statistically significant due to a relative high incidence of early carcinomas of the oral cavity among the oldest patients (Table 2).

The change in our treatment policy resulted in an apparent skew towards either surgery or radiotherapy alone, in the group of older patients $(\mathrm{p}=0.0011$, Table 2$)$. Radiotherapy alone, or combined with neo-adjuvant chemotherapy, was for several years the preferred treatment in advanced disease, especially for the group $\leq 65$ years [4]. There was no difference in peri- and postoperative deaths or in serious complications between the two age- groups.

The incidence of residual loco-regional disease following completion of treatment was significantly higher in the group of the older patients (Table 3). Recurrences, on the other hand, were more frequently observed among the patients $\leq$ 65 years of age $(p=<0.001)$. Salvage treatment, both locally and regionally, was successful in 94 patients. There was no pronounced difference in loco-regional recurrences or salvagere when T1a glottic carcinoma were left out. This observation strongly suggests that early glottic carcinoma rarely recur, and thus have prognosis. 
Table 2. Clinical Data According to Age Groups

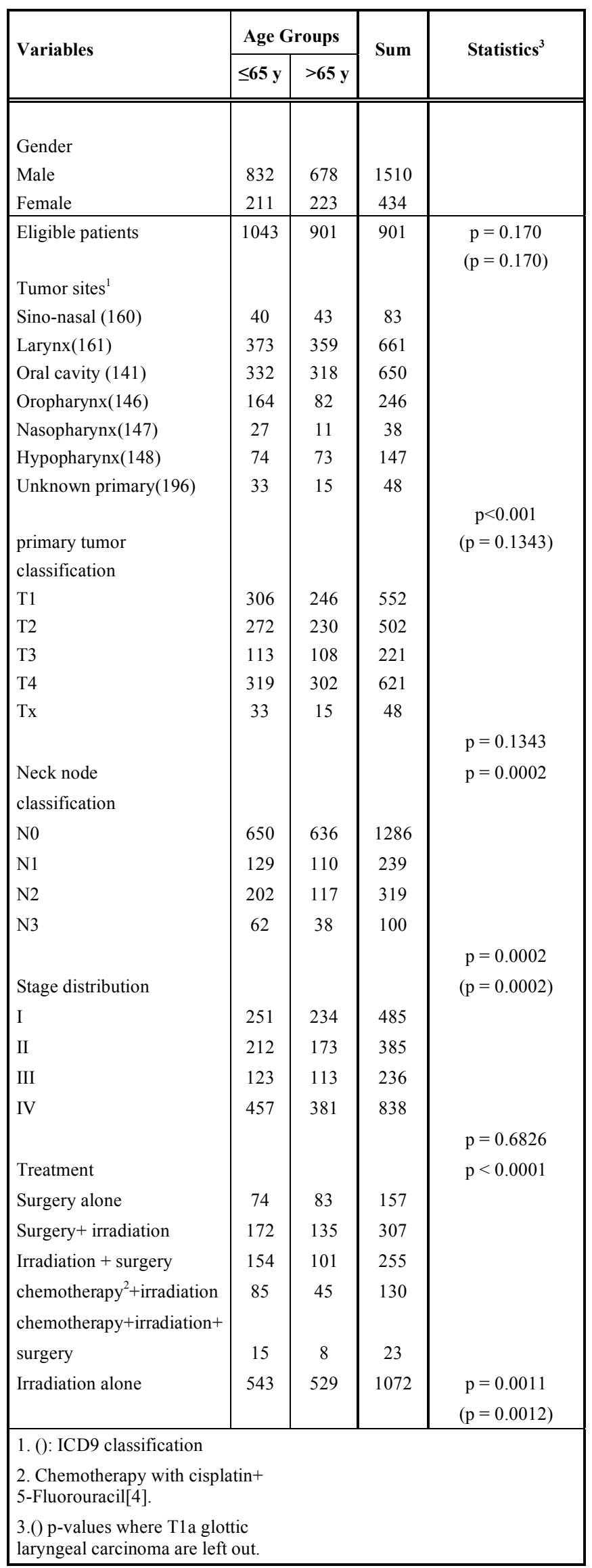

Table 3. Failures (Recidual Disease Following Treatment and Recurrences) According to Age Groups

\begin{tabular}{|c|c|c|c|c|}
\hline \multirow{2}{*}{ Failures } & \multicolumn{2}{|c|}{ Age Groups } & \multirow{2}{*}{ Sum } & \multirow{2}{*}{ Statistics $^{4}$} \\
\hline & $\leq 65 y$ & $>65 y$ & & \\
\hline Residual tumor ${ }^{1}$ & 100 & 265 & 365 & $p=001$ \\
\hline Locally & 121 & 144 & 265 & $\mathrm{p}=0.0051$ \\
\hline Regionally & 66 & 70 & 136 & $\mathrm{p}=0.2141$ \\
\hline Recurrences $^{2}$ & $324(321)$ & $208(205)$ & 0 & $\begin{array}{c}\mathrm{p}<00001 \\
(\mathrm{p}<0.0001)\end{array}$ \\
\hline Locally & $212(210$ & $1338(131)$ & 0 & $\begin{aligned} \mathrm{p} & =0.0014 \\
(\mathrm{p} & =0.0016)\end{aligned}$ \\
\hline Regionally & $72(79)$ & $54(53)$ & 0 & $\begin{array}{l}\mathrm{p}=0.1686 \\
(=0.1537)\end{array}$ \\
\hline Distant & 45 & 36 & 81 & $\mathrm{p}=7257$ \\
\hline Salvage $^{3}$ & $73(71)$ & $22(22)$ & 94(94) & $\begin{array}{c}0.5810 \\
(p=0.5784)\end{array}$ \\
\hline Locally & $61(60)$ & $17(17)$ & $78(77)$ & $\begin{aligned} \mathrm{p} & =0.04999 \\
(\mathrm{p} & =0.51804)\end{aligned}$ \\
\hline Regionally & $10(10$ & $4(4)$ & $14(14)$ & $\begin{aligned} \mathrm{p} & =0.6031 \\
(\mathrm{p} & =0.6206)\end{aligned}$ \\
\hline Distant & 2(2) & $1(1)$ & $3(3)$ & $\mathrm{p}=0.6031$ \\
\hline \multicolumn{5}{|c|}{$\begin{array}{l}\text { 1. } 13 \text { patients had residual disease both } \\
\text { locally and regionally }\end{array}$} \\
\hline \multicolumn{5}{|c|}{$\begin{array}{l}\text { 2. } 11 \text { patients had recurrences at more } \\
\text { than one site simultaneously }\end{array}$} \\
\hline \multicolumn{5}{|c|}{$\begin{array}{l}\text { 3. Alive with no evidence of } \\
\text { disease. }\end{array}$} \\
\hline \multicolumn{5}{|c|}{$\begin{array}{l}\text { 4.() figures and } \mathrm{p} \text {-values where } \mathrm{T} 1 \mathrm{a} \\
\text { glottic squamous cell carcinoma are left out. }\end{array}$} \\
\hline
\end{tabular}

A total of 199 secondary primary tumours (including 9 synchronous tumours) within the aero-digestive tract were observed (Table 4). The upper aero-digestive tract, especially the oral cavity, was the dominant site of a secondary primary tumour. The annual incidence of such tumours was 2.3 and 4.3 for patients $\leq 65$ years and $>65$ years, respectively. Secondary lung carcinomas increased to 66 with approximately equal annual incidence. A majority of the secondary lung carcinomas was diagnosed after the $70^{\text {th }}$ birthday. Secondary tumours as cause of death were equal when comparing the two age groups.

Table 5 presents the outcome, according to site and age. Patients with laryngeal cancer represents the largest group of patients, and these patients experienced the most advantageous course, which might be an effect of likely is a relatively high number of $\mathrm{T} 1$ tumours. For pharyngeal tumours, the older patients were in the worst situation. Fig. (1) shows that patients $\leq 65$ had a significantly better diseasefree survival than the group with the older patients $(p=0.105)$. When comparing the outcome for patients $65-75$ 
Table 4. Second Primary Tumors According to Age Groups

\begin{tabular}{|c|c|c|c|c|c|}
\hline \multirow{3}{*}{$\begin{array}{l}\text { Sitesec. } \\
\text { prim. }\end{array}$} & \multicolumn{4}{|c|}{ Age-Groups } & \multirow{3}{*}{ Sum/Mean } \\
\hline & \multicolumn{2}{|r|}{$\leq 65 \mathrm{y}$} & \multicolumn{2}{|r|}{$>65 y$} & \\
\hline & No. & Mean No. /Year (Range) & No. $(\%)$ & Mean No. Annually (Range & \\
\hline Head and & & 2,3 & & 4,3 & 3,3 \\
\hline Neck & 78 & $(0-17.8)$ & 37 & $(0-12.9)$ & 115 \\
\hline \multirow[t]{2}{*}{ Oesophagus } & 12 & 3,3 & 6 & 1,5 & 18 \\
\hline & & $(0-10,7)$ & & $(0.2-2.3)$ & \\
\hline \multirow[t]{2}{*}{ Lung } & 45 & 2,3 & 21 & 1,5 & 1,9 \\
\hline & & $(0,1-12,5$ & & $(0,1-9.7)$ & 66 \\
\hline No., mean/year & 135 & 2,6 & 64 & 3,2 & 199 \\
\hline (range) & & $(0-17.8)$ & & $(0-12.9)$ & $(0-17.8)$ \\
\hline Patients dead sec. prim. & 89 & & 41 & & 130 \\
\hline$(\%)$ & $(6.6)$ & & $(6.4)$ & & $(6.5)$ \\
\hline
\end{tabular}

years of age with those older than 76 , the older had the poorest survival (Fig. 2), but still there was an appreciable number of the older patients who escaped their HNCC.

Combined treatment, irrespectively of whether radiotherapy was given pre- or postoperatively, showed the best results, when compared to monotherapy, principally radiotherapy. For radiotherapy alone, the disease- specific survival was $44 \%$ and $28 \%$ for patients $\leq 65$ and $>65$ years respectively. The diseasespecific survival was independent of gender.

\section{DISCUSSION}

This study focuses on the disease -specific survival of elderly patients with SCCHN, considered physically and mentally fit for the treatment with curative intent. Several recent studies have established co-morbidity as an independent predictor of survival in elderly patients (age $\geq 65$ years) $[5,6]$ A malignant disease may aggravate comorbidity illnesses or vice versa. There are certainly in this, as in comparable materials, patients with significant concomitant illnesses who did not preclude treatment, but that might have affected survival unfavourably. There is, however, no way to identify these patients with certainty, and/or to judge the impact of their comorbidity on survival. As most patients in this study had surgery as part of the treatment, the ASA index, which since the 1960s has been used as a simple prognostical description of a patient's physical state as an exclusion criterion, has been used [2]. Patients with an ASA index of $\geq 4$ (life threatening diseases, not necessarily related to the primary disease) were considered unfit for the treatment and consequently were excluded from this study. Roughly seen, the ASA classification emphasizes the same disadvantageous conditions as does the co-morbidity indices in use [6]. Likewise, treatment was withheld when patients were considered mentally unfit for treatment. The percentage of patients excluded $(7.9 \%)$ from treatment in this study is similar to that previously reported from a comparable institution in Canada [7].

Table 5. Outcome According to Age Groups

\begin{tabular}{|c|c|c|c|c|c|c|c|c|c|}
\hline \multirow{3}{*}{ Site } & \multicolumn{8}{|c|}{ Age-Groups } & \multirow{3}{*}{ Total No. } \\
\hline & \multicolumn{4}{|c|}{$\leq 65 y$} & \multicolumn{4}{|c|}{$>65 y$} & \\
\hline & Aned & Dfd & Dod & Sum & Aned & Dfd & Dod & Sum & \\
\hline Sino-nasal & 13 & 23 & 4 & 40 & 6 & 17 & 20 & 43 & 83 \\
\hline Larynx & 181 & 65 & 127 & 373 & 142 & 66 & 151 & 359 & 661 \\
\hline Oral cavity & 132 & 121 & 79 & 332 & 79 & 126 & 113 & 318 & 650 \\
\hline Nasopharynx & 8 & 11 & 8 & 27 & 2 & 2 & 7 & 11 & 38 \\
\hline Oropharynx & 60 & 59 & 45 & 164 & 13 & 42 & 27 & 82 & 246 \\
\hline Hypopharynx & 14 & 42 & 18 & 74 & 8 & 44 & 21 & 73 & 147 \\
\hline Unknown primary & 13 & 9 & 11 & 33 & 4 & 6 & 5 & 15 & 48 \\
\hline All & 421 & 330 & & 1043 & 254 & 303 & 344 & 901 & 1944 \\
\hline
\end{tabular}

Abbrevations: Aned: Alive no evidence of disease, Dfd: Dead from disease, Dod: Dead other disease. 


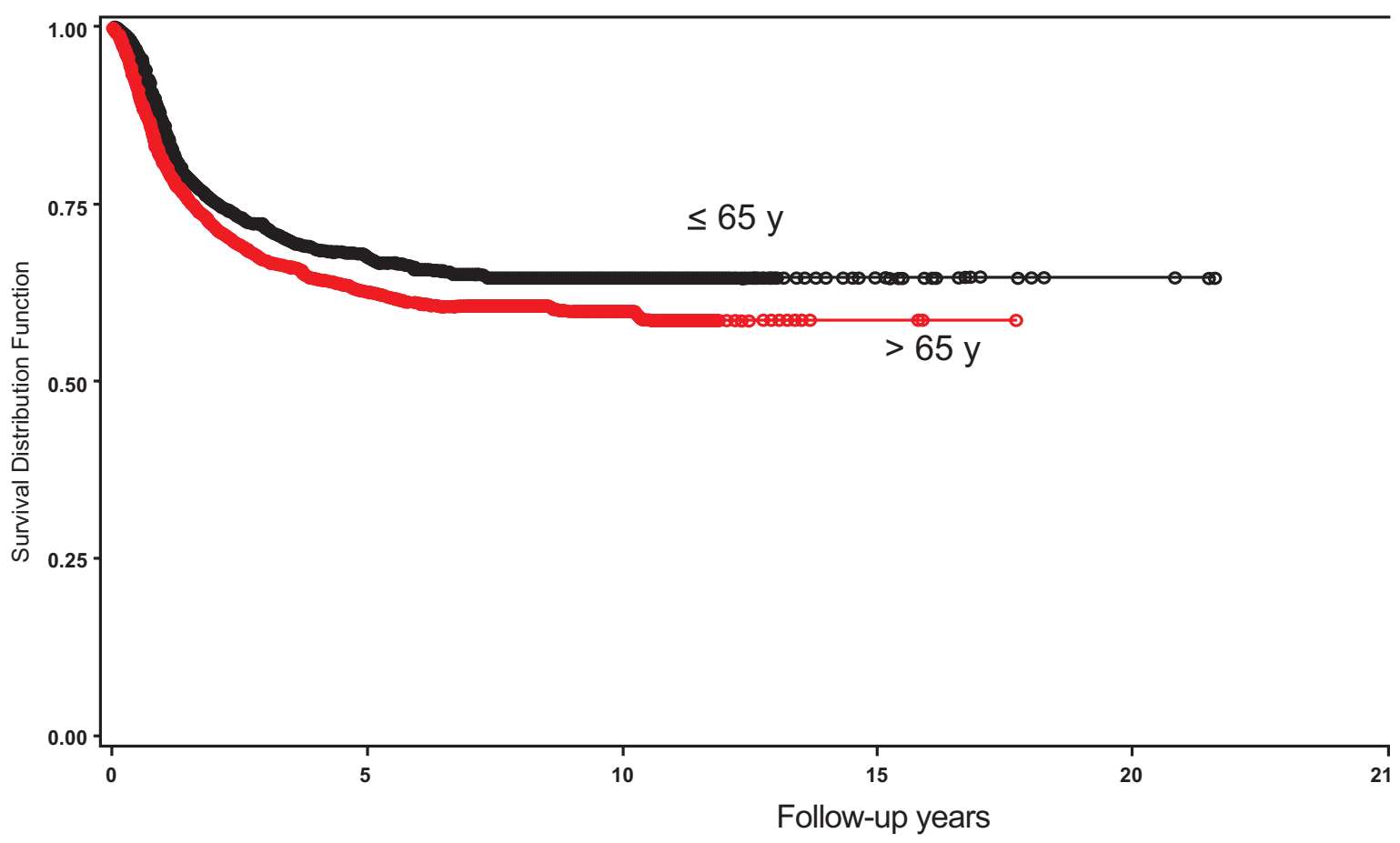

Fig. (1). Disease-specific survival for patients $\leq 65 v s>65$ years of age (failed/total: $330 / 1049 v s$ 303/901; (p $<0.143)$.

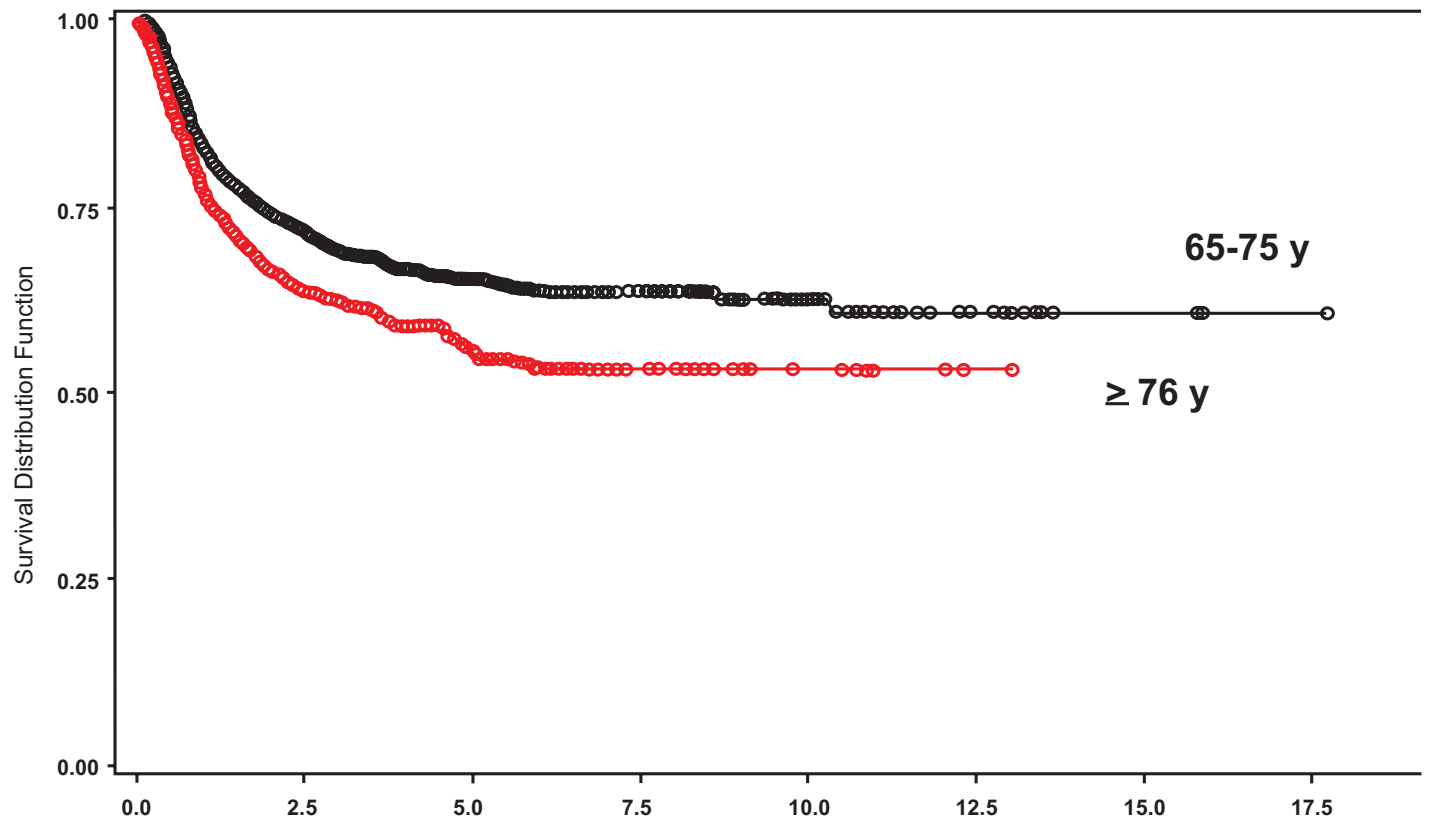

Follow-up years

Fig. (2). Disease-spesific survival for patients 65-75 vs $\geq 76 y e a r s$ of age (failed/total: $192 / 603 v s$ 111/603; p $<0.105$ ).

As life expectancy increases, clinicians increasingly face the challenge of treating elderly patients with cancer, including some types of head and neck carcinomas [8]. It has been estimated that in Norway the number of persons older than 70 will be increased by $40 \%$ by 2020 (Source: Ministry of Health and Welfare). This increase in the number of old patients with cancer, combined with increasing costs related to medical management, force clinicians to concern themselves with the effect of age on survival.

Paucity of well controlled materials and conflicting reports limit our knowledge of the disease- specific survival of the older patients with SCCHN $[1,8]$. Several factors may 
explain the lack of attention to this topic and the contradicting results, the major limitations probably being that it has been difficult to accumulate a sufficiently large number of patients with long follow-up, and that most studies presented are retrospective $[9,10]$. Other methodological issues, such as unequivocal criteria for tumour sites, stage, histology, inclusion and exclusion, are also some features that should be accurately accounted for.

The classification of age, with a cut-off at 65 years that coincides with the average age is similar to that used in several other studies [5-7]. This age cut- off might also contribute to a reduction of the impact of co-morbidity in the group of the older patients. This material thus satisfies the strict and compulsory criteria for evaluation, proposed by Lacy and co-workers for this kind of studies [9].

In contrast to some reports [9-11], it was our observation, as well as that of others $[12,13]$ that the older patients in general had less advanced disease. This distribution of stage in favour of the older patients was accentuated after exclusion of the early stage glottic carcinomas. There was no difference in extent of the disease, when comparing those excluded from the treatment with those included and thus no selection bias.

Clinicians may be inclined to treat older patients less aggressively than younger. This reluctance toward treating elderly patients may be attributed to a presumed lower tolerance of radiation toxicity and fear of postoperative complications and morbidity in these patients [14]. Although the group of patients older than 65 had the poorest survival rate, the fact that $40 \%$ of the patients older than 65 were alive and free of disease at the closure of this study, strongly suggests that treatment is worthwhile in patients at an advanced age, regarding the disease- free survival for SCCHN. This observation concurs with observations in materials similar to the present study $[1,13]$. Other reports further substantiate the opinion that age in itself is not an independent prognostic factor, neither is it in itself a decisive factor for survival of SCCHN [9,11,15-17]. On the other hand, Davidson and co-workers [18] showed in a material of oral tongue squamous cell carcinoma matched for age, gender, site, stage and treatment that an increase of 10 years in age was associated with an $18 \%$ increase in diseasespecific mortality. Both surgery $[17,19,20]$, even when combined with free-tissue graft reconstruction [19], and radiotherapy [10, 20-22] offer commendable results in older patients. Moreover, the incidence of peri- and postoperative complications has been reported to be independent of age $[14,20]$. Radiotherapy appears to be well tolerated by elderly patients and does not generate drastically different side effects when compared to that experienced by younger patients $[14,21]$. Cisplatin based regiments have been widely employed in primary and recurrent treatment of SCCHN. Argiris and co-workers [22] report that elderly fit patients ( $>70$ years) with metastatic or recurrent disease had response rates similar to younger patients, but the older patients suffered a higher rate of toxicity. These authors strongly warn against a therapeutic nihilistic attitude towards chemotherapy in the treatment of elderly patients. Novel chemo-radiation treatment schemes [23] might also become a useful treatment option for elderly patients.
A recent prospective study shows that the impact of treatment on quality of life after one year did not differ when elderly and younger patients with head and neck cancer were compared [14]. However, a large longitudinally prospectively recorded study from Sweden and Norway reveals that the quality of life in patients older than 65 with cancer of the head and neck continue to deteriorate up to 5 years following treatment [24]. The adverse effect of treatment on quality of life varies with the site of the primary tumours, being least pronounced for patients treated for laryngeal carcinoma and worst for those with pharyngeal carcinoma $[25,26]$.

Contrary to others $[10,11]$ this study showed the highest incidence of secondary malignancies of the aero- digestive tract among the group with the older patients. This may, to some extent, be an effect of insufficient observation time. Whether the same factors causing the initial tumour, principally alcohol and tobacco consumption [27], are also accountable for the secondary tumours in older patients, is debatable. It has recently been shown that P53 mutations are less common in older patients, and based on this observation, it has been suggested that accumulation of spontaneous mutations during lifetime and defective DNA repair mechanisms may play an important role in the carcinogenesis in elderly patients [10]. In addition to faulty DNA repair, an aging immune surveillance [1] and previous radiotherapy [28] might partly to some extent explain the reduced incidence of secondary malignancies among older patients.

\section{SUMMARY}

An assumed prejudiced and erroneous conception of a poor tolerance to treatment of older patients may lead to undertreatment. This should no longer be the case. When properly monitored, conventional therapies seem feasible for older patients.

Although co-morbidity may play an important role regarding the disease-free survival age at diagnosis, is in itself no contraindication for treatment. The site, stage or intrinsic characteristics of the tumour appear to be equally important determinants of the prognosis. Radiotherapy, surgery and chemotherapy have been reported to be well tolerated and with encouraging results in aged patients. Granted a satisfactory physical and mental condition, there is no reason why elderly people should be withheld appropriate treatment that could delay or prevent the misery, suffering and disability that a persistent or progressive head and neck cancer entail. Most likely, treatment of elderly patients might also prove cost favourable. This issue should be an object to further analysis.

\section{ACKNOWLEDGEMENTS}

My sincere thanks to Dr. Terje Osnes, M.D., Ph.D. for the advice regarding the presentation and to Maj Boysen for linguistic advice.

\section{REFERENCES}

[1] Jones AS, Beasley N, Houghton D, Husband DJ. The effects of age on survival and other parameters in squamous cell carcinoma of the oral cavity, pharynx and larynx. Clin Otolaryngol 1997; 23: 51-6. Gwinnutt C. Lecture notes on clinical anaesthesia. $2^{\text {nd }}$ ed. Blackwell Science Ltd 2004. 
[3] Boysen M, Lövdal O, Natvig K, Winther FÖ. Value of follow-up in patients treated for Squamous cell carcinoma of the head and neck. Eur J Cancer 1992; 28: 426-30.

[4] Lewin F, Damber L, Jonsson H, et al. Neoadjuvant chemotherapy with cisplatin and 5-fluorouracil in advanced squamous cell carcinoma of the head and neck; a phase III study. Radiother Oncol 1997; 43: 23-8; 1998; 23: 51-6.

[5] Alho O-P, Hannula K, Loukkala A, et al. Differential prognostic impact of comorbidity in head and neck cancer. Head Neck 2007; 29: 913-8.

[6] Hall SF Rochon PA, Streiner DL, Paszat LF, Groome PA, Rohland SL. Measuring comorbidity in patients with head and neck cancer. Laryngoscope 2002; 112: 1988-96.

[7] Hall SF, Boysen M, Groome PA, Mackillop W. Squamous cell carcinoma of the head and neck in Ontario, Canada and in southeastern Norway. Laryngoscope 2003; 113: 695-701.

[8] Derks W, de Leeuw R, Winnubst J, Hordijk GJ. Eldely patients with head and neck Cancer. Physical, social and psychological aspekts after 1 year. Acta Otolaryngol 2004; 124: 509-14.

[9] Lacy PD, Piccirillo JF, Merritt MG, Zequeira MR. Head and neck squamous cell carcinoma: Better to be young. Arch Otolaryngol Head Neck Surg 2000; 122: 253-8.

[10] Koch WM, Patel H, Brennan J, Boyle JO, Sidransky D. Squamous cell carcinoma of the head and neck in the elderly. Arch Otolaryngol Head Neck Surg 1995; 121: 262-5.

[11] Pytynia KB, Grant JR, Etzel CJ, et al. Matched analysis of survival in patients with squamous cell carcinoma of the head and neck diagnosed before and after 40 years of age. Arch Otolaryngol Head Neck Surg 2004; 130: 869-73.

[12] Barzan L, Veronesi A, Caruso G, et al. Head and neck cancer and aging: a retrospective study in 438 patients. J Laryngol Otol 1990; 104: 634-40.

[13] Sarini J, Fournier C, Lefebvre J-L, et al. Head and neck squamous cell carcinoma in elderly patients. A long-term retrospective review of 273 cases. Arch Otolaryngol Head Neck Surg 2001; 127: 108992.

[14] Derks W, de Leew JR, Hordijk GH, et al, Elderly patients with head and neck cancer: short term effects of surgical treatment on quality of life. Clin Otolaryngol 2004; 28: 399-405.

[15] Pitman KT, Johnson JT, Wagner RL, et al. Cancer of the tongue in patients less than forty. Head Neck 2000; 22: 297-302.
[16] Brundage WJ. Treatment of cancer in the elderly. In: Muss HB, Hunter CP, Johnson KA, Eds. Taylor \& Francis, New York 2006; pp. 385-409.

[17] Bhattacharyya N. A matched survival analysis for squamous cell carcinoma of the head and neck in the elderly. Laryngoscope 2003: $113 ; 368-72$.

[18] Davidson BJ, Root WA, Trock BJ. Age and survival from squamous cell carcinoma of the oral tongue. Head Neck 2001; 23: 273-9.

[19] Lusinchi A, Bourhis J, Wibault P, et al. Radiation therapy for head and neck cancers in the elderly. Int J Radiat Oncol Biol Phys 1990; 18: 819-23.

[20] Clayman GL, Eicher SA, Sicard MW, et al. Surgical outcomes in head and neck cancer patients 80 years of age and older. Head Neck 1998; 20: 216-23.

[21] Metges JP, Eschwege F, de Crevoisier R, et al. Radiotherapy in head and neck cancer in the elderly. A challenge. Crit Rev Oncol Hematol 2000; 34: 195-203.

[22] Argiris A, Li Y, Murphy BA, Langer CJ, Forastiere AA. Outcome of elderly patients with recurrent or metastatic head and neck cancer treated with Cisplatin-based chemotherapy. J Clin Oncol 2004; 22: 262-68.

[23] Argis M, Karamouzis MV, Raben C, Ferris RL. Head and neck cancer. Lancet 2008; 371; 1695-709.

[24] Abendstein H, Nordgren M, Boysen M, et al. Quality of life and head and neck cancer. A five year prospective study. Laryngoscope 2005; 15: 2183-92.

[25] Nordgren M, Abendstein H, Jannert M, et al. Health-related quality of life five years after diagnosis of laryngeal cancer. Head Neck 2003; 56: 133-43.

[26] Nordgren M, Abendstein H, Jannert M, et al. Health-related quality of life in patients with pharyngeal carcinoma: A five-year followup. Head Neck 2005; 28; 339-49.

[27] Rothman K, Keller A. The effect of joint exposure to alcohol and tobacco on risk of cancer of the mouth and pharynx. J Chronic Dis 1972; 25: 711-6.

[28] Rennemo E, Zätterström U, Boysen M. Reduced risk of head and neck second primary tumors after radiotherapy. Radiother Oncol 2009 [Epub ahead of print]. 